\title{
Falls in the community: state of the science
}

This article was published in the following Dove Press journal:

Clinical Interventions in Aging

5 June 2013

Number of times this article has been viewed

\begin{abstract}
Amy L Hester ${ }^{\prime}$
Feifei $\mathrm{Wei}^{2}$

'Clinical Informatics and Innovation, ${ }^{2}$ Department of Biostatistics, Fay W Boozman College of Public Health, University of Arkansas for Medical Sciences Medical Center, Little Rock, AR, USA
\end{abstract}

Correspondence: Amy L Hester Department of Nursing, University of Arkansas for Medical Sciences Medical Center, 430 I W Markham St \#526 Little Rock, AR 72205-7199, USA

Tel + I 50 I 6868877

$\mathrm{Fax}+$ I 50I 5263889

Email hesteramyl@uams.edu

\begin{abstract}
Falls and fall-related injuries among older community-dwelling adults continue to be a major health concern in the US. Falls are the leading cause of disability and trauma-related death in persons over 65 years of age. This article discusses current approaches in community fall management and challenges with these approaches, and offers some insight for community providers regarding this issue.
\end{abstract}

Keywords: community falls, patient care planning, risk assessment, aged

\section{Background National}

Falls and fall-related injuries among older community-dwelling adults continue to be major health problems in the US. ${ }^{1}$ In community-dwelling adults aged 65 years or older, one in three suffers a fall each year. ${ }^{2,3}$ In those over 80 years of age who live in the community, $50 \%$ sustain a fall each year. ${ }^{4,5}$ Falls have been the leading cause of injury and injury-related deaths for over a decade, and represent the single most common cause for trauma-related hospital admission in this population. ${ }^{1,6-8}$

In 2008 alone, more than 19,700 adults aged 65 years or older died from fallrelated injuries. In 2009, 2.2 million fall-related injuries among adults aged 65 years or older were treated in emergency departments, and more than 581,000 of the patients involved were hospitalized. ${ }^{7}$ In 2000, the direct medical cost of fatal fall injuries in the US totaled \$179 million and the direct cost of caring for nonfatal falls was \$19 billion,

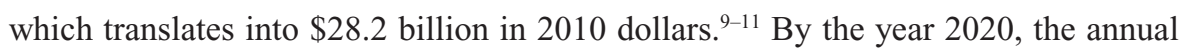
direct and indirect costs are predicted to rise to $\$ 47$ billion in 2010 dollars. ${ }^{12}$

Brain injuries and injuries to the hips, legs, and feet are the most fatal and costly of fall injuries, accounting for $78 \%$ of fatalities and $79 \%$ of fall-related costs. ${ }^{11}$ Occurring in $33 \%$ of nonfatal falls, fractures are the most common and costly fall injuries, and account for $61 \%$ of nonfatal fall-related costs. ${ }^{11}$ Other consequences of falls that are more difficult to quantify in such terms include loss of mobility, functional decline, loss of independence, psychological consequences, social impact, and institutionalization. ${ }^{8,9,13-15}$ The purpose of this article is to describe the process of falls and injury management in the community setting and discuss issues with each step in this process.

\section{Local}

To investigate the impact of falls locally, a data warehouse query was performed to measure how many patients aged 65 years and older were treated for fall-related 
injuries at an academic medical center in the south central US, which is the only level 1 trauma center in that state. The query identified a total of 51,138 patients aged over 65 years and treated for all causes from January 2007 to June 2012. Demographic information for these patients is shown in Table 1. International Classification of Diseases, 9th Revision, Clinical Modification (ICD-9-CM) diagnosis codes were used to identify patient visits related to falls, identified by $E$ codes $880-888$, and to identify the primary diagnoses for these fall-related patient visits. ${ }^{16}$ Of these 51,138 individuals, $4363(9 \%)$ were treated for various injuries related to fall events during 6130 episodes of care. These episodes of care represented visits to all points of entry, including hospital, emergency department, and outpatient clinic visits. Further examination of the primary medical coding for these individuals revealed that $1566(36 \%)$ suffered a head injury or fracture from their fall (Table 2). Although these data do not take into account individuals who received medical care at other neighborhood facilities for their falls, it does provide an insight into the percentage of the most severe fall-related injuries (fractures and head injuries) among patients who seek medical care for falls. It also provides an understanding as to the volume of fall-related care that single hospitals provide. This high incidence of serious fall-related injuries has clinical significance for this group in particular because fractures and head injuries are the most common cause of

Table I Demographic characteristics of patients aged 65 and older treated between January I, 2007 and June 30, 2012

\begin{tabular}{llll}
\hline Race & \multicolumn{3}{l}{ All patients $\geq \mathbf{6 5}$ years } \\
\cline { 2 - 4 } & Female & Male & Total \\
\hline Ethnic category & & & \\
$\quad$ Hispanic or Latino & 96 & 63 & 159 \\
$\quad$ Not Hispanic or Latino & $28,86 \mathrm{I}$ & 21,266 & 50,127 \\
$\quad$ Unknown/refused to answer & 426 & 426 & 852 \\
Total of all subjects & 29,383 & 21,755 & 51,138 \\
Racial categories & & & \\
American Indian/Alaska Native & 36 & 26 & 62 \\
Asian & 129 & 80 & 209 \\
Native Hawaiian or other & 2 & 1 & 3 \\
Pacific Islander & & & \\
Black or African-American & 4637 & 2360 & 6997 \\
White & 24,057 & 18,799 & 42,856 \\
More than one race & 0 & 0 & 0 \\
$\quad$ Unknown/refused to answer & 522 & 489 & 1011 \\
Total of all subjects & 29,383 & 21,755 & 51,138 \\
Age, years & & & \\
65-74 & 15,582 & 12,570 & 28,152 \\
75-84 & 9529 & 7135 & 16,664 \\
85+ & 4272 & 2050 & 6322 \\
Total of all subjects & 29,383 & 21,755 & 51,138 \\
\hline
\end{tabular}

Table 2 Total number of patients aged 65 years and older with falls/injurious falls between January I, 2007 and June 30, 2012

\begin{tabular}{|c|c|c|c|}
\hline & ICD-9-CM diagnosis codes & $\begin{array}{l}\text { Patients } \\
\text { (n) }\end{array}$ & $\begin{array}{l}\text { Episodes } \\
\text { (n) }\end{array}$ \\
\hline Falls & E880-888 & $4363(9 \%)$ & 6130 \\
\hline \multirow{12}{*}{$\begin{array}{l}\text { Injurious } \\
\text { falls }\end{array}$} & E880-888 and any of the & & \\
\hline & following: Primary diagnosis & & \\
\hline & of any codes shown below: & & \\
\hline & Intracranial injury 850-854.xx & & \\
\hline & Head injuries 959.01 & & \\
\hline & Fracture of skull $800-804 . x x$ & & \\
\hline & Fracture of neck and trunk & & \\
\hline & 805-809.xx & & \\
\hline & Fracture of upper limb & & \\
\hline & $810-819 . x x$ & & \\
\hline & Fracture of lower limb & $1566(3 \%)$ & 1759 \\
\hline & $820-829 . x x$ & & \\
\hline Total & & 51,138 & \\
\hline
\end{tabular}

Abbreviation: ICD-9-CM, International Classification of Diseases, 9th Revision, Clinical Modification.

long-term disability and institutionalization in persons over 65 years of age.

\section{Issues of falls and injury management}

As demonstrated above, falls and injury management in the community setting remains a prevalent issue. As in the hospital setting, the process of fall and injury management in older community-dwelling adults starts with risk assessment. ${ }^{17}$ Beyond that step, the two settings are vastly different in their approaches to care. The process of fall management in the community setting and issues surrounding it are described below.

\section{Risk assessment}

Risk assessment for the older community-dwelling adult generally takes place in the clinic and home health settings, and is done by physicians, therapists, and licensed nursing staff. Accuracy of risk assessment tools including inter-rater reliability, sensitivity, and specificity remains an important issue to consider across settings. It is also important to consider which fall prediction instruments are most appropriate given the history of the patient, the resources available, and the setting in which they are being used. ${ }^{18}$ Several risk screening and assessment tools for use in the community setting are available. Fabre et $\mathrm{al}^{18}$ argue that rapid screening tools may not identify the actual risk factor for or cause of a fall, and those tools that are comprehensive in nature cannot be easily delivered in community-based settings. Other literature suggests that currently used fall risk assessment 
tools are becoming outdated and are used infrequently in community dwellers when compared with those who are hospitalized. ${ }^{19}$ Fabre et al argue that "development and use of comprehensive falls risk screening tools that identify and weight falls risk factors is encouraged among researchers and clinicians and should be a focal point of falls prevention research." 18

In the hospital setting, there is ample time and opportunity for assessing fall risk and care planning for falls and injury prevention because patients are generally hospitalized for several days. Whereas patients in hospital are typically assessed for fall risk at least daily, providers in the community setting have less time and opportunity to assess fall risk. The opportunity to assess risk for the older community-dwelling adult is therefore dependent on how often they seek outpatient care. In the community setting, assessment of fall risk is typically performed annually, ${ }^{18}$ and time spent with care providers is finite, with face to face time often lasting a few minutes. The only available risk assessment tool for the outpatient setting that takes less than a minute to complete is the Timed Get Up and Go Test. All other validated fall risk assessment tools used in the outpatient setting require $15-20$ minutes to complete, ${ }^{20}$ which is a barrier to their use, particularly in the clinical setting. Table 3 provides psychometrics for the commonly used adult outpatient fall risk assessment tools.

\section{Planning of care}

Although not as strictly regulated by agencies in the outpatient setting, attention to fall prevention is mandated by The Joint Commission and the Medicare Payment Advisory Commission. ${ }^{21}$ As in the hospital setting, care planning in the community is aimed at mitigating the risk of falls. Here, care plans are less formal and rely on effective education and communication with patients and families during periodic visits that are often unrelated to fall prevention. Similar to risk assessment, education can require significant time to complete, especially if the patient is complex or cognitively impaired. This often results in clinicians relying on brochure-type education provided to the patient and family at the end of their visit, instead of face to face education where there is an opportunity for questions and clarification of individual issues.

Another problem with prevention of falls in the community setting is that management of falls in this setting is under the purview of several types of clinicians practicing in different settings under varying incentive and reimbursement schemes. ${ }^{21}$ Barriers to incorporating fall prevention into practice include lack of knowledge on the part of the clinician about falling as a preventable condition, perceived lack of expertise, insufficient reimbursement for fall prevention services, and inadequate referral patterns among clinicians. ${ }^{21,22}$ These issues are further confounded by increasing numbers of older adults, who represent the fastest growing segment of the US population. As the needed number of community-based health care providers continues to grow, this trend will make it even more difficult for existing providers to meet the needs of this ageing population. ${ }^{23}$

Recognizing the enormous challenges of reducing falls among older adults in the community setting, the US Federal Government passed the Safety of Seniors Act of 2007. This bill amended the Public Health Services Act, authorizing the Secretary of Health and Human Services to oversee and support a national education campaign for fall prevention and to expand grant opportunities for studies that focus on risk assessment and both fall and injury reduction specifically for older adults. ${ }^{24}$ The impact of this bill remains to be seen. In addition, the Centers for Disease Control and Prevention has spent over $\$ 24$ million in fall-related research and programs over the last 20 years. ${ }^{25}$ Access to free fall prevention guides is available on the Centers for Disease Control and Prevention website at www.cdc.gov.

\section{Event reporting and benchmarking}

Event reporting and benchmarking do not hold the same imperatives for community-based fall and injury management

Table 3 Psychometric statistics of commonly used adult outpatient fall risk assessment tools ${ }^{20}$

\begin{tabular}{|c|c|c|c|c|c|}
\hline Scale name & $\begin{array}{l}\text { Berg balance } \\
\text { test }\end{array}$ & $\begin{array}{l}\text { Elderly fall } \\
\text { screening test }\end{array}$ & $\begin{array}{l}\text { Dynamic gait } \\
\text { index }\end{array}$ & $\begin{array}{l}\text { Timed get up } \\
\text { and go }\end{array}$ & $\begin{array}{l}\text { Tinetti performance } \\
\text { oriented mobility }\end{array}$ \\
\hline Sample size & No data & 361 & 133 & 30 & 79 \\
\hline Optimum cut score & 49 & 3 & 19 & 14 & 10 \\
\hline Inter-rater reliability & 0.95 & No data & No data & 0.98 & 0.90 \\
\hline Sensitivity & $77 \%$ & $93 \%$ & $85 \%$ & $87 \%$ & $80 \%$ \\
\hline Specificity & $86 \%$ & $78 \%$ & $38 \%$ & $87 \%$ & $74 \%$ \\
\hline
\end{tabular}

Notes: Table content reused with permission from Oxford University Press. Perell KL, Nelson A, Goldman RL, Luther SL, Prieto-Lewis N, Rubenstein LZ. Fall risk assessment measures: an analytic review. J Gerontol A Biol Sci Med Sci. 200 I;56(I2):M76I-M766. 
programs as they do for the inpatient setting. Falls that occur in the community are usually captured at the national level by insurance claims data. Local analysis of fall-related events, such as that presented in Tables 1 and 2, is difficult and time-consuming to perform without the resources of a data warehouse. However, by using approaches to collect the data in Tables 1 and 2, and by utilizing Medicare data on medically consulted falls, we could establish a communitywide event reporting system and set up benchmarks for community-dwelling adults aged 65 years and older. In addition to Medicare data, data warehouses affiliated to care facilities can be utilized for event reporting and benchmarking. The requirement for a data warehouse to participate in the national benchmarking system is that its affiliated care facilities need to uniformly and consistently code all fall-related events using E-880-888 and the extent of injuries using adequate ICD-9-CM codes for all patients seen not only in emergency departments but also in outpatient clinics. Benchmarking in this way would allow community providers insight as to the magnitude of falls and fall-related injuries in their respective communities and would allow for comparisons between communities. Such comparisons may allow community providers to collaborate more effectively to prevent falls and injuries in the community setting.

\section{Discussion}

Falls and fall-related injuries are high-risk, high-volume, and high-cost events ${ }^{26}$ in the community setting. ${ }^{27}$ Complex relationships between providers and the changing and diverse needs of patients make managing and sustaining fall and injury reduction a difficult endeavor. Most fall research among older community-dwelling adults has focused on multifactorial interventions to minimize the risk of falling. Other research has focused on development of assessment tools for identifying those at risk for falls. ${ }^{28}$ While studies have found some successful approaches to reducing community-based falls, ${ }^{21,23,29}$ incorporation of their findings into practice has been limited due to lack of time, poor motivation of target populations, and insufficient cooperation between health care providers. ${ }^{30}$ This has resulted in even positive research findings having little impact on the overall problem. It is unknown if the Safety of Seniors Act of 2007 will be a catalyst for changing the current trends in community-based fall prevention efforts.

In a time of declining reimbursement, staffing shortages, and need for outcome transparency, clinicians need clarity on how to provide preventive patient care as efficiently as possible. ${ }^{31,32}$ Most of the previous fall research has focused on preventing all fall events in all patients. Undeniably, preventing falls prevents injuries. However, approaching injury management from only this perspective has been unsuccessful in affecting the overall issue, especially in the community setting. Increased effort specifically towards prediction and prevention of injury may provide a more efficient and successful approach. Future research should concentrate on identifying and predicting those persons specifically at risk for injurious falls, which would allow health care providers to target and intensify interventions to those most at risk for falls with injury. This would provide clinicians with a more focused and effective approach to specific management of injurious falls, which are the most harmful and costly to the community.

\section{Acknowledgment}

ALH and FW were partly supported by the National Center for Research Resources, National Institute of Health, US Department of Health and Human Services through grant \#1UL1RR029884.

\section{Disclosure}

The authors report no conflicts of interest in this work.

\section{References}

1. Kannus P, Palvanen M, Niemi S, Parkkari J. Alarming rise in the number and incidence of fall-induced cervical spine injuries among older adults. J Gerontol A Biol Sci Med Sci. 2007;62(2):180-183.

2. Hausdorff JM, Rios DA, Edelberg HK. Gait variability and fall risk in community-living older adults: a 1-year prospective study. Arch Phys Med Rehabil. 2001;82(8):1050-1056.

3. Hornbrook MC, Stevens VJ, Wingfield DJ, Hollis JF, Greenlick MR, Ory MG. Preventing falls among community-dwelling older persons: results from a randomized trial. Gerontologist. 1994;34(1):16-23.

4. Rubenstein LZ, Josephson KR. The epidemiology of falls and syncope. Clin Geriatr Med. 2002;18(2):141-158.

5. Soriano TA, DeCherrie LV, Thomas DC. Falls in the communitydwelling older adult: a review for primary-care providers. Clin Interv Aging. 2007;2(4):545-554.

6. Abdelhafiz AH, Austin CA. Visual factors should be assessed in older people presenting with falls or hip fracture. Age Ageing. 2003; 32(1):26-30.

7. Centers for Disease Control and Prevention, National Center for Injury Prevention and Control. Web-based Injury Statistics Query and Reporting System (WISQARS). Available from: http://www.cdc.gov/injury/ wisqars. Accessed May 3, 2013.

8. Stevens JA. Falls among older adults: public health impact and prevention strategies. Generations. 2002-2003;26(4):7-14.

9. Lee A, Mills PD, Watts BV. Using root cause analysis to reduce falls with injury in the psychiatric unit. Gen Hosp Psychiatry. 2012;34(3): 304-311.

10. Rubenstein LZ. Falls in older people: epidemiology, risk factors and strategies for prevention. Age Ageing. 2006;35 Suppl 2:ii37-ii41.

11. Stevens JA, Corso PS, Finkelstein EA, Miller TR. The costs of fatal and non-fatal falls among older adults. Inj Prev. 2006;12(5):290-295.

12. Wu S, Keeler EB, Rubenstein LZ, Maglione MA, Shekelle PG. A costeffectiveness analysis of a proposed national falls prevention program. Clin Geriatr Med. 2010;26(4):751-766. 
13. Alexander BH, Rivara FP, Wolf ME. The cost and frequency of hospitalization for fall-related injuries in older adults. Am J Public Health. 1992;82(7):1020-1023.

14. Sterling DA, O'Connor JA, Bonadies J. Geriatric falls: injury severity is high and disproportionate to mechanism. J Trauma. 2001;50(1): 116-119.

15. Vellas BJ, Wayne SJ, Romero LJ, Baumgartner RN, Garry PJ. Fear of falling and restriction of mobility in elderly fallers. Age Ageing. 1997; 26(3):189-193.

16. Center for Injury, Policy and Practice, San Diego State University. Falls Prevention December 11, 2003 Teleconference Handout 2. Cause of Fall Codes- ICD-9 and ICD-10. Available from: http://www.cippp.org/ teleconf/falls-c03.pdf. Accessed May 3, 2013.

17. Tinetti ME. Factors associated with serious injury during falls by ambulatory nursing home residents. J Am Geriatr Soc. 1987;35(7):644-648.

18. Fabre JM, Ellis R, Kosma M, Wood RH. Falls risk factors and a compendium of falls risk screening instruments. J Geriatr Phys Ther. 2010; 33(4):184-197.

19. Unsworth J. Falls in older people: the role of assessment in prevention and care. Br J Community Nurs. 2003;8(6):256-262.

20. Perell KL, Nelson A, Goldman RL, Luther SL, Prieto-Lewis N, Rubenstein LZ. Fall risk assessment measures: an analytic review. J Gerontol A Biol Sci Med Sci. 2001;56(12):M761-M766.

21. Tinetti ME, Baker DI, King M, et al. Effect of dissemination of evidence in reducing injuries from falls. $N$ Engl J Med. 2008;359(3):252-261.

22. Tinetti ME, Gordon C, Sogolow E, Lapin P, Bradley EH. Fall-risk evaluation and management: challenges in adopting geriatric care practices. Gerontologist. 2006;46(6):717-725.

23. Banez C, Tully S, Amaral L, et al. Development, implementation, and evaluation of an Interprofessional Falls Prevention Program for older adults. J Am Geriatr Soc. 2008;56(8):1549-1555.
24. The 112th United States Congress. Available from: http://www. opencongress.org/bill/110-s845/show. Accessed May 3, 2013.

25. Sleet DA, Moffett DB, Stevens J. CDC's research portfolio in older adult fall prevention: a review of progress, 1985-2005, and future research directions. J Safety Res. 2008;39(3):259-267.

26. Nelson A, Powell-Cope G, Gavin-Dreschnack D, et al. Technology to promote safe mobility in the elderly. Nurs Clin North Am. 2004;39(3): 649-671.

27. Apold J, Quigley PA. Minnesota Hospital Association Statewide Project: SAFE from FALLS. J Nurs Care Qual. 2012;27(4):299-306.

28. Currie L. Fall and injury prevention. In: Hughes RG, editor. Patient Safety and Quality: An Evidence-Based Handbook for Nurses. Rockville, MD: Agency for Healthcare Research and Quality; 2008.

29. Petridou ET, Manti EG, Ntinapogias AG, Negri E, Szczerbinska K. What works better for community-dwelling older people at risk to fall? A meta-analysis of multifactorial versus physical exercise-alone interventions. J Aging Health. 2009;21(5):713-729.

30. Milisen K, Geeraerts A, Dejaeger E; Scientific Working Party, Uniform Approach for Fall Prevention in Flanders. Use of a fall prevention practice guideline for community-dwelling older persons at risk for falling: a feasibility study. Gerontology. 2009;55(2):169-178.

31. Graham BC. Examining evidence-based interventions to prevent inpatient falls. Medsurg Nurs. 2012;21(5):267-270.

32. Pappas SH. The cost of nurse-sensitive adverse events. J Nurs Adm. 2008;38(5):230-236.

33. Vassallo M, Vignaraja R, Sharma JC, Briggs R, Allen S. The relationship of falls to injury among hospital in-patients. Int J Clin Pract. 2005; 59(1):17-20
Clinical Interventions in Aging

\section{Publish your work in this journal}

Clinical Interventions in Aging is an international, peer-reviewed journal focusing on evidence-based reports on the value or lack thereof of treatments intended to prevent or delay the onset of maladaptive correlates of aging in human beings. This journal is indexed on PubMed Central, MedLine, the American Chemical Society's 'Chemical Abstracts Ser-

\section{Dovepress}

vice' (CAS), Scopus and the Elsevier Bibliographic databases. The manuscript management system is completely online and includes a very quick and fair peer-review system, which is all easy to use. Visit http://www.dovepress.com/testimonials.php to read real quotes from published authors. 